\title{
A review of composite structures subjected to dynamic loading
}

\author{
P.R. Hampson, M. Moatamedi * \\ Stress Analysis Research Group, Institute for Materials Research, University of Salford, \\ Manchester, M5 4WT, UK \\ * Corresponding author. Tel.; +44 (0) 161295 4512; fax: +44 (0) 1612955575 \\ E-mail address: m.moatamedi@salford.ac.uk (M. Moatamedi).
}

\begin{abstract}
The following review of composite impact work summarises key research interests and provides a brief overview for the development of theoretical, experimental and numerical methods for low, high, and hyper velocity impact. Particular attention is given to experimental apparatus and techniques used for the different impact velocity regimes, and the implementation of failure criteria in finite element (FE) modelling methods which predict material behaviour. Areas are then identified for which limited research has been currently undertaken and suggestions are made for possible future research topics.
\end{abstract}

Keywords: Composites; impact behaviour; failure criterion; finite element.

\section{INTRODUCTION}

This literature review provides a summary of composite material impact research and forms the basis of a progressive focussing exercise in order to identify the opportunity for original research in a field which ensures relevance to the scientific community and industry.

The following section addresses some of the earlier impact testing methodology for composites and shows the progression of experimental techniques. Next, we provide a general overview of low velocity impact testing, which primarily uses drop-weight impact apparatus. The fourth section reviews high velocity impact work, which is predominately the study of the ballistic limits of composite armours using gas-gun and shock tube apparatus. Then follows the section covering the relatively new field of hyper velocity impact and its relevance to space structures. The final section concludes the review by suggesting the need for future research for the understanding of composite impact characterisation. 


\section{EARLY IMPACT TESTS}

Many of the early investigations into the impact response of composite materials conducted in the 1970's, utilised testing methods already developed for the testing of metal specimens with techniques such as Izod, Charpy and Hounsfield tests.

In order to determine some of the mechanical properties of composites, in 1970, Hazell [1] conducted some strain rate experiments using an instrumented Hounsfield tensometer. This work was later continued in 1971 [2] but this time using an instrumented Izod impact pendulum to gather data within the speed range of 0.5 to $3.5 \mathrm{~m} / \mathrm{s}$.

In 1971, Hancox [3] used the Izod impact test to study carbon-fibre reinforced plastics (CFRP) and found that impact energy increased with increasing fibre volume fraction. In this work, Hancox acknowledges that many of the CFRP test specimens manufactured to dimensions recommended by British Standards failed to break. This is perhaps one of the earliest indications that experimental techniques used for testing metals may not be suitable for the testing of composites.

In the same year Wells and Hancox [4] used three-point loading tests to show that the flexural strength and stiffness of glass-fibre composite beams could be increased by applying a carbon-fibre layer to the top and bottom to create a hybrid sandwich beam. To investigate the properties of the hybrid, further test were conducted in 1973 [5] this time using the Izod test to measure impact strength, flexural modulus and flexural strength. To overcome Hancox's previous experience of test specimens failing to break under test [3], the dimensions of the test samples were restricted to $12.7 \mathrm{~mm}$ wide and $2.5 \mathrm{~mm}$ thick, which was below the recommended British Standard dimensions for the testing of laminated plastics but did however ensure that all specimens would fail under impact conditions.

In 1975, Harris and Bunsell [6] progressed their own work on the tensile study of hybrid carbon and glass fibre composites [7] and the work of Hancox and Wells [5] to further study the impact properties of hybrid composites using the Charpy impact test. Their investigation found that for notched test specimens, the impact energy varied in a mixturerule manner for the proportions of glass reinforced plastic (GRP) and CFRP, and that flexural modulus varied linearly with volume fraction.

Also in 1975, Perry and Adams [8] used Charpy test apparatus to investigate the impact response of graphite/epoxy hybrid composites and concluded that material/layup combination played a significant factor in the impact energy absorption capabilities of the test specimens. It was also found that increased impact properties were usually at the expense of a poorer static performance.

Although these early impact investigations provided an insight into the various properties of composites, many authors [9-13] were having reservations as to whether Izod and Charpy impact tests were actually providing useful experimental data for the design of composite structures. This was because the test specimen geometries were unrepresentative 
of structural applications and therefore their validity for composite component design was unreliable.

As a result of this, some researchers had already begun to develop impact experiments for composites that moved away from the traditional methods associated with metal testing. Instead they started to utilise low velocity drop-weight impact rigs and high velocity gas gun arrangements, to test composite flat plate geometries, which provided a more accurate representation of actual structural applications.

In 1971, Rogers et al. [9] used an air-gun to conduct high speed ballistic impact tests on square composite laminates, to determine if impact resistance could be improved by treating the fibre surface with sodium hypochlorite. The authors state that the air-gun proved to be a suitable experimental apparatus for the study of small particle impact on composite materials.

In 1972, Wrzesien [10] investigated the use of wire sheet reinforcements for glass-fibre composites in order to improve their resistance to high velocity impact, using an air-gun. The study identified that wire sheets provided an improvement to both impact resistance and containment of the damaged area.

In 1973, Thomas [11] used a non-instrumented drop-weight impact rig to investigate the effect of environmental attack on the impact strength of glass fibre reinforced polyester and concluded that a scratch or notch on the surface and in the presence of an attacking media could result in reduced composite impact performance.

In a similar fashion to Hancox and Wells [5], Thomas also deviated from British Standards for impact testing to better suit his requirements by choosing to study circular plates as opposed to the recommended square ones. The explanation given by Thomas for this was it aided the production of test specimens with a particular glass content. Once again, this highlighted the fact that there was a lack of standard procedures for testing the impact response of composite materials.

Further progression in the impact resistance of composite plates was provided in 1973 by Ross and Sierakowski [12]. Together they looked at the influence of filament orientation, volume fraction, and different combinations of filaments and found that the geometrical arrangement of fibres was of great importance in the resulting post-impact fracture pattern and energy dissipation properties of the composite material.

\section{LOW VELOCITY IMPACT}

In 1976, McQuillen et al. [14] used drop-weight tests to investigate the impact response of graphite/epoxy composite laminates in the velocity range of $0-6 \mathrm{~m} / \mathrm{s}$. The author's state impacts up to $6 \mathrm{~m} / \mathrm{s}$ can be regarded as a structural dynamic response phenomenon and therefore in-plane and transverse wave effects can be neglected. Based on this assumption 
they developed an analytical model that provided a good correlation with the experimental data.

In 1983 and 1984, Cantwell et al. [15, 16] conducted drop-weight impact tests on a range of 16 ply carbon fibre laminates with either all non-woven plies or mixtures of woven and non-woven plies. Damaged coupons were then subjected to fatigue tests. In 1986, they then went on to test the impact performance of CFRP reinforced with high-strain carbon fibres [17]. Further work was conducted by Cantwell and Morton in 1989 [18] which investigated the effects of specimen geometry on the perforation threshold of circular CFRP test samples, and in 1990, the post impact performance of CFRP was assessed [19].

In 1987, Curtis [20] investigated the mechanical properties of composite materials inline with Composites Research Advisory Group (CRAG) recommendations which also included subjecting the test coupons to a drop weight impact test.

In 1989, Morton and Godwin [21], compared the impact response of carbon fibre composites for two different stacking sequences and target geometries.

In 1984, Caprino et al. [22] showed that a simple formula based on an energy approach could predict the quasi-elastic behaviour of a composite structure under impact. In the same year, Caprino et al. [23] followed on from this work to derive an energy model which could predict the maximum contact force during a low velocity impact. This model was validated with instrumented drop-weight apparatus for three different types of composite materials. The authors concluded that the model was valid when vibrational and damping phenomena did not have a significant role in the impact response.

During the early 1990's, Kumar et al. [24-26] used gas-gun apparatus to investigate impact damage of CFRP and GFRP laminate plates. Kumar et al. stated that most previous studies on low velocity impact damage had used drop weight experimental methods of a relatively large mass, which represented the accidental damage caused by dropped tools. The authors therefore concluded that research into barely visible impact damage (BVID) caused by smaller masses had been neglected and proposed the use of a gas gun to fire small projectiles at velocities less than the ballistic limit, but high enough to cause BVID. Much of their work focused on the energy dissipation during impact and study of the resulting delaminations.

In the later part of the 1990's, Found et al. investigated the behaviour of circular CFRP laminates when subjected to single and multiple low velocity impacts and found that for single impacts it was the impact force that strongly governed the damage as opposed to the impact energy [27]. Their work also looked at the size effects of the test specimens used in these investigations and reported that increased panel size appeared to affect the threshold of perforation [28]. In 1998, Found et al. [29] developed a spring-mass model which described the drop weight impact response of CFRP panels. This paper also provided a detailed description of the low velocity impact apparatus they had used for their investigations. 
Some work for the improved impact resistance of composites had utilised sandwich sections of a honeycomb core with CFRP skins [30-45]. Found et al. [46, 47] argued that this type of structure was difficult to repair and therefore stated that the use of local stiffeners had been recognised as a viable means of reinforcing the structural stiffness of CFRP skins. As a result of this they investigated the behaviour of T-blade stiffened CFRP panels [46-48] and found that for impacts conducted inline with the stiffener, the perforation energy had increased and the maximum damage occurred at higher impact energies [47].

In 1995, Pavier and Clarke [49] published a paper about replicating impact damage artificially on composite laminates and comparing their mechanical performance to real damaged specimens. To generate the different impact energies for the experiment, the mass of the impactor was varied as opposed to selecting different drop heights which was held constant at $1 \mathrm{~m}$ as recommended by the widely used CRAG specification for impact tests.

In the latter part of the 1990's, Ganapathy et al. [50] studied the nonlinear finite element static analysis and subsequent estimation of damage and its growth in laminated composite circular and rectangular plates. Their study used a 4-noded, 48 degree of freedom doubly curved quadrilateral shell developed by Venkatesh and Rao [51]. The damage analysis applied the Tsai-Wu [52] quadratic failure criterion to all Gauss points and the mode of failure was identified by using the maximum stress criteria.

The same methodology was then applied to the study of laminated composite cylindrical and spherical shell panels subjected to low-velocity impact $[53,54]$. Ganapathy et al. reported that the main mode of material failure was matrix cracking along the direction of the fiber and the effect of curvature was to increase the overall damage of the test specimen. The damage experienced by the spherical shell panel was found to be more than that for a cylindrical shell panel of same dimensions, since the former was stiffer than the latter.

In 1996, Madjidi et. al. [55] presented the results to an experimental investigation of the damage tolerance of chopped strand mat (CSM) when subjected to low velocity oblique impacts. In the introduction to this paper our attention is drawn to the fact that a great deal of research had previously been conducted into the response of composites subjected to normal impacts but little had been done with regard to oblique collisions. The authors also argued that most impacts are actually oblique in nature and therefore justification could be made for this type of research.

Since this experimental study considered oblique contact angles, the impactor was constrained to movement in the vertical direction by the use of two guide rods. In using this technique the impactor could only rebound off the test specimen vertically and therefore a post-collision residual velocity determined. This method called for an additional term in the energy balance equations to account for the strain energy imparted to the guide rods. 
The fundamental conclusions were that residual tensile strengths increased as plate inclination increased; the normal impact force was of greater importance than the tangential force in causing gross damage to specimen plates; and for any given impactor strike energy, perpendicular impacts were shown to be more damaging than oblique impacts. Unfortunately the paper didn't include a numerical comparison.

In 1997 Kim and Goo [56] investigated the dynamic contact behaviours of laminated curved composite plates by a rigid elliptic impactor. In the same year, Kim et al. [57] also published a paper which investigated the effects curvature of CFRP laminates could have on dynamic response and impact-induced damage. Some interesting points were addressed throughout the paper such as the coupling issues between matrix cracking and delamination, which are the two main failure modes of low velocity impact and hence require accurate numerical modelling. An important assumption the authors used with regard to this low velocity failure coupling was that the initial mode of composite failure would be intraply matrix cracks. Fibre breakage was less important in this study since it is more associated with high velocity impacts. The importance of delamination was discussed because it degrades the stiffness and strength of composites and also alters the natural frequency and damping coefficient. Under compressive loading, delamination was particularly important as this can cause the delaminated area to open up further and induce local buckling. The main conclusion of the paper was that greater delamination areas were produced on cylindrical panels than for flat plates when subjected to the same impact velocity, this was due to curvature effects which caused the maximum impact force to be higher and the impact duration to be longer. Therefore greater attention is required for the design and maintenance of curved structures because they are more susceptible to impact damage.

In the late 1990's Kistler and Waas [58-60] reported on the low velocity impact of curved laminate panels. Their studies covered in detail the numerical approach [58] and analytical approach [59]. Continuing the work of other researchers [61-63] in 1999, Kistler and Waas [60] made comparisons of force-deformation curves for low velocity impact and static conditions. For ease of comparison with published data on flat plate geometry [64, 65], this study used comparable impact specimen geometries and impact conditions. They reported that as plate thickness decreases, deformations increase and curvature effects became increasingly important. The authors also noted that for nonlinear curved plate impact, the bending and membrane effects needed to be considered because they are more important than inertia effects for the low velocity impact conditions.

In 1998, Collombet et al. [66-68] studied the impact behaviour of laminated composites with additional focus on damage criteria and numerical modelling methods. The key methodology behind these papers was the use of a hybrid approach which combined experimental tests and numerical modelling (within the explicit FE code, PLEXUS) to predict matrix cracking and delamination in glass-epoxy laminated plates when subjected to heavy mass / low velocity impact. 
The finite element model used an averaging technique to consider the local effects of matrix cracks. This was done by calculating the elastic characteristics of a homogenised, undamaged material, which was equivalent to the initial cracked material.

To model delamination, a contact-impact technique was used which represented delamination as a local loss of contact between the nodes of interfaces. In order for the numerical model to determine where delamination was likely to take place, the matrix cracking and delamination coupling was modelled as a combination of the available subjective experimental observations within numerical conditions.

The experimental observations showed that delaminations appeared at the interface of two cracked layers and that delamination initiation and propagation was strongly dominated by matrix cracking. It was also shown that after the initiation of delamination, the continuing propagation would follow the direction of the fibres in the lower ply and, therefore, for modelling purposes the cracked state of the upper ply was less important.

In 1999, Leylek et.al. [69] presented a paper discussing the modelling of impact on curved fibre composite panels. For this study, the numerical solutions were compared to published experimental data and they found that non-linear explicit simulation gave reasonably accurate results. They stated that computational impact simulation of composite structures was still a relatively new area of research and that a further understanding of impact damage mechanisms was required.

The results showed that as the radius of curvature of the panel was increased, the impact contact force decreased until it levelled at a constant value. The use of high mesh densities had little effect on the results especially at low impact energy levels. Poor results were noted however for low mesh densities at higher impact energies.

In 2000, Schoeppner and Abrate [70] used the Air Force Research Laboratory's (AFRL) low velocity impact database to determine delamination threshold loads for several types of composite laminates. This was done by examining the load-time histories from different impact experiments and identifying the impact load at which detectable damage had initiated.

The information contained within the AFRL database is a compilation of several experimental programs by various researchers and therefore some of the post impact evaluation data varies in its content. However, all impact tests were conducted on the commercially available Dynatup GRC 8250 impact rig.

An interesting point to note is the use of a test sample support method which had previously been shown to approximate simply supported boundary conditions and was similar to a fixture used by NASA.

The authors note that the delamination threshold load was taken as the point at which a significant damage initially occurs in the test specimens and does not reflect the overall 
damage caused by the impact. In the discussion it was stated that the data further demonstrated the presence of a delamination threshold load for low velocity impact and that it could be identified on the load-time history curve irrelevant of the impact energy. The relevance of this work meant that if the peak loading of a laminate is known, and it is below the experimentally determined delamination threshold load, then no significant damage is expected to occur. This allows engineers to design structures resistant to serious low velocity impact damage in cases where the peak loading impact threat is known.

In the same year, Hou et al. [71] published a paper on impact damage prediction for CFRP T300/914 composite plates and suggest an improved failure criterion for the FE software LS-DYNA3D. It was noted that in numerical simulations delamination occurred before matrix cracking and fibre breakage, but experimentally the opposite was true. Several explanations for this anomaly were presented such as the fact that only stresses in one plane $\left(\sigma_{11}, \sigma_{12}, \sigma_{22}\right)$, were considered by the software and therefore limitations would be apparent when out of plane stresses became significant.

The fact that delamination occurred before matrix cracking and fibre breakage meant that the stress raising effects of the latter two damage modes wasn't considered when determining delamination. More importantly however, the sign of the through-thickness stress, $\sigma_{33}$, was neglected and therefore the compression/tension effects where treated the same despite compressive stress being better at constraining delamination and tension being a promoter of delamination.

Based on these identified limitations, the authors proposed an improved failure criterion which constrained delamination when through-thickness compression was applied, and also improved the matrix cracking and fibre breakage criteria by considering shear stresses in different planes.

For efficient numerical modelling, only one quarter of the structure was modelled due to symmetry. The numerical investigation utilized the pre-processor PATRAN to generate the model, DYNA3D as the solver, and D3PLOT for post-processing. For increased numerical accuracy the meshing was denser around the impact zone.

For the experimental work the authors elected to use a gas gun arrangement and chose to ensure that the impact geometry was the same as that used in the aerospace industry by Airbus [72] and Boeing [73], thus the impactor was fitted with a spherical ended steel cap $16 \mathrm{~mm}$ in diameter and rubber bungs used to dampen the force signal oscillation.

Overall, the authors observed that the modified delamination model provided results in agreement with experimental results (i.e. constrained delamination caused by throughthickness compressive stress). The area where delamination did not occur in the impact zone was greater in the model than the experimental observations which suggested that a small amount of delamination should be permitted if the compressive stress was small. As a result of this finding, the authors recommended that further study for the interaction 
between through-thickness compression and shear stress needed to be made and in 2001, Hou et al. [74] addressed this issue and developed a delamination criterion for laminated composites under low velocity impact.

For this study, the fibre failure and matrix cracking criteria remained unchanged. The main difference was for the delamination criterion where damage coefficients were introduced for matrix cracking, $d_{m s}$, and fibre failure, $d_{f s}$, for which the coefficients had a value of 1 when no damage was present and gradually reduced to 0 as failure occurred. A third parameter was also introduced, $\delta$, which monitored the ratio between interlaminar shear stresses before and after the occurrence of matrix or fibre failure. A value of 0 was assigned for $\delta$, when no fibre of matrix failure was present, i.e. $d_{m s}$ and $d_{f s}$ equal a value of 1 .

A further significant variation for this study was the change of the stress reduction association for the through-thickness stress, $\sigma_{33}$, which was altered from a fibre failure damage mechanism to a delamination mechanism.

It was found that these modifications to the delamination criterion, which were developed in the preceding paper [71], gave numerical results in closer agreement with experimental results. Despite this being the case, the problem of the predicted delamination free impact region being greater than that for the experimental test still presented itself.

In 2001, Abrate [75] published a paper describing different modelling techniques which could be applied to the impact dynamics of composite structures. In general there were four categories considered: energy-balance models which assume a quasi-static condition; spring-mass models which simplify the dynamics of the structure; complete models in which the full behaviour of the structure is modelled; and finally, a model for impact on infinite plates.

In the discussion on the validity of using an infinite plate model, several issues were raised such as impact wave propagation and the negligible effects of shear deformation when the size of the deformed zone was large when compared to the plate thickness. In general, if the deformation wave front has not reached the boundary of the plate, then the infinite plate model can be confidently used in the analysis. If the wave propagation reflects on the plate boundaries back to the point of impact, then the finite size of the test sample must be take into account.

The paper suggests that for some types of impact problems the energy absorbed by the indentation of a composite test specimen could be a significant factor and therefore must be modelled adequately in the analysis. For this purpose, Abrate presents us with the Hertz contact law which considers the contact force history of a local indentation during the loading and unloading phases of the impact.

In 2001, Mili and Necib [76] studied the behaviour of E-glass/epoxy circular composite plates when subjected to a low velocity aluminium projectile impact. Three different cross- 
ply laminates were investigated and measurements of the impact time history, projectile displacement and plate deflection were recorded. A theoretical model based on the Hertzian contact law was used to validate the experimental results but unfortunately the scope of the paper did not include a numerical analysis.

The authors justify this investigation by arguing that much of the theoretical study of low velocity impact of laminated composites has been based on a quasi-static approach and the predictive capability of the analytical methods needed to be compared to experimental data.

The Hertzian contact law was developed by using a single degree of freedom spring-mass model approximation. It was found that generally the impact theory agreed reasonably well with the experimental data. The study did however show that composite specimens dissipate the incident projectile energy differently to metals.

One drawback to the theoretical modelling was the assumption that the contact specimen behaved elastically and therefore the indentation, $\alpha$, caused by the impact, returned to a value of zero once contact had ceased. This could be improved by modelling the local plastic deformation.

In 2001, Azouaoui et al. [77] carried out an investigation into the modelling of damage and failure of E-glass/R368 epoxy composite plates when subjected to low velocity impact fatigue. The author's stated that composite materials are extremely sensitive to damage caused by impacts and the understanding of resulting delamination phenomenon is still limited. Although research has previously been conducted to study the residual strength after impact at various energy levels, little work had been done to investigate the effect of fatigue on composites [27, 78-86]. The work which had been done usually had difficulty in establishing a good correlation between composite damage and residual strength properties.

The experimental investigation utilised an impact fatigue apparatus which consisted of a crank mechanism to provide cyclic impacts. From the test results, graphs of damage evolution against number of impacts were plotted. These graphs revealed that there were three distinct damage regimes. The first was the initiation and growth of delaminated surfaces. The second regime marked the end of any further delamination and was termed the point of 'delamination saturation'. The third and final stage was identified by an acceleration of the damage which was due to ply cracking and fibre breakage. The impact fatigue was found to seriously reduce the bending stiffness of the composite plates, and low impact energies were still large enough to cause internal delaminations that caused a loss of laminate strength even though there was no visible signs of damage.

Between 1999 and 2003 Caprino et al. [87-91] published several papers regarding the development of an empirical law for the prediction of indentation and penetration of composites. Much of the work involved the use of static loading and low velocity impact testing to verify results. Of great interest is the paper published in 2003 [91], in which the authors acknowledged that the power-law equation proposed in their earlier work [88] for relating indentation with impact energy was inadequate when composite penetration was 
approached, and therefore not as generally applicable as first thought. The new equation proposed in the later work addressed this issue by adapting the formula so that the constants were independent of material properties.

In 2003, Krishnamurthy et al. [92] continued their earlier work on the study of composite shells [93] and the work previously done by Kim et al. [57] and Ganapathy and Rao [54] in order to develop an impact damage prediction model based on the Choi-Chang failure criteria [94-96]. The authors state that the applicability of the Choi-Chang model requires additional experimental investigation for higher impactor velocities.

In 2004, Whittingham et al. [97] stated that most research for low speed impact had been conducted on unstressed test samples and very few cases investigated the behaviour of uniaxally and biaxially pre-stressed coupons. For this paper the response of pre-stressed composite laminated plates subjected to low velocity impact were investigated. The study found that for low impact energies (below 6J) the peak loading, energy absorption and penetration/perforation depth were independent of pre-stress, but for energies above $6 \mathrm{~J}$, the effect of pre-stress became more significant.

The study investigated carbon-fibre/epoxy composites; which is relevant to the aerospace industry; especially since most structures (even stationary aircraft) experience complex loading states. Whittingham et al. stated that aircraft fuselage skins can typically experience strains up to $1500 \mu \varepsilon$ and wing skins can be subjected to strains in the region of $3000 \mu \varepsilon-$ $4500 \mu \varepsilon$.

The experimental study employed the use of a low velocity, drop weight impact rig to test the impact response of composites when subjected to uniaxial tension, biaxial tension, shear and unstressed states.

Only the observable impact damage was assessed in this study, but as low speed impact usually results in barely visible impact damage, then most of the damage in this study would be undetected. The authors do acknowledge this and state that a more accurate assessment would be made using thermography and ultrasonic $\mathrm{C}$-scan methods in a subsequent paper.

After this work was completed the same research team were joined by a fifth member, R. Thomson, and went on to investigate the effect different impactor shapes have on the impact response of thin woven carbon/epoxy laminates [98]. The specimens were tested on the same drop weight test rig as before for impact energies of 4 and $6 \mathrm{~J}$ using three different shaped impactors; hemispherical, ogival and conical, all $12 \mathrm{~mm}$ in diameter.

The authors stated that most research into the effect of impactor shape had been conducted for the high speed impact regime where the ballistic limit of projectile shapes has been investigated for impact resistant armour. At high speeds however, the damage is likely to be 
localised but for low speed a more global response from the test specimen is expected and therefore this type of investigation could be justified.

As expected the conical impactor imparted the most energy to the test specimen and the hemispherical impactor subjected the specimen to the highest peak force and the lowest contact duration. For the lowest impact energy, only the hemispherical impactor produced barely visible impact damage whilst the other two impactors resulted in permanent indentation and penetration.

Since the different impactor shapes induced different damage mechanisms, this meant the residual properties of the composite specimen would vary also depending on the type of impactor, in some cases there could be up to $60 \%$ reduction in strength. This is an important consideration when impact testing composites.

In 2006, Zhang et al. [99] presented a damage model to predict the initiation and propagation of matrix cracking and delamination in carbon-epoxy laminated plates. This model used a contact constraint that was based on a penalty function method which considered potential delamination and matrix cracking areas as a cohesive zone, and the damage process as a contact behaviour between the plate interfaces. It was found that the numerical results were in good agreement with low velocity impact experimental observations.

In 2004, Her and Liang [100] conducted a numerical investigation using ANSYS/LSDYNA finite element software to investigate low velocity impact of composite plate, cylinder, and doubly curved shell structures.

Zhao and Cho [101], also investigated damage initiation and propagation in composite shells when subjected to low velocity impact. This paper, published in 2007 stated that there was still a requirement for damage prediction studies for low velocity impact on composite laminate shells since most previous work had considered flat plates whereas most applications of composite materials are geometrically curved.

For their study, they considered three failure modes, matrix cracking, fibre breakage, and delamination. The numerical investigation was conducted on a specially developed finite element program which was verified against existing numerical and experimental data for laminated composites.

The FE program utilised a progressive failure technique which used an eight-node nonconforming element with Taylor's modification scheme to measure interlaminar stress distribution, internal damage pattern, and progressive failure. The Tsai-Wu failure criterion was employed to perform damage analysis and predict failure. Since the Tsai-Wu criterion cannot differentiate between damage modes, the authors used an additional formula to determine the mode of failure. For this, they used Tsai's degenerate stiffness criterion in conjunction with the Tsai-Wu criterion. 
Through their studies, the authors found that the maximum damage area occurred on the top surface for shells, but on the lower surface for plates. The damage response of the plates could be explained by the bending caused by the lateral impact and hence greatest damage appears on the bottom.

The scope of the paper also covered issues such as the effect of laminate stacking sequence, thickness, and radius of curvature and it was found that all of these played a considerable role in the overall impact response. The most interesting was the sensitive effect of stacking sequence and number of interfaces, for which the authors suggest the requirement for an optimisation process when designing composite shells.

In 2006, Hosseinzadeh et al. [102] published their results to an investigation of the damage behaviour of Carbon fibre reinforced composite plates when subjected to drop weight impacts. For this study, four commercially available composite plates were tested;

(i) thin glass fibre reinforced plastic (GFRP): woven long fibre

(ii) thick glass fibre reinforced plastic (GFRP): woven long fibre

(iii) carbon fibre reinforced plastic (CFRP): non-woven long fibre

(iv) carbon glass fibre reinforced plastic (CGFRP): woven mixed mat long fibre hybrid.

All samples were $270 \times 270 \mathrm{~mm}$ and were clamped uniformly on all four edges.

The numerical analysis was conducted with ANSYS LS-DYNA V6.1, using shell elements to model the plates and utilised the Chang-Chang failure criterion [103] to model progressive damage. Overall the software did not compare very well with experimental observations for post-failure behaviour of the plates, i.e. damage zone geometry. The software did however, predict the damage threshold reasonably well and therefore could be used as a design tool for similar plates to determine if failure will occur or not.

For the different composite test samples, it was found that carbon fibre reinforced composite plates showed the best structural behaviour under low velocity impact, but the hybrid plate (carbon/glass) showed better behaviour for high impact energies. A crucial point that the authors state in their summary is that hybrid composites offer the best solution for industrial applications, especially for aerospace since the hybrid composites have 30\% less weight than GFRP. The hybrid material also makes good use of the benefits for both glass and carbon fibres.

\section{HIGH VELOCITY IMPACT}

During the 1970's and early 1980's, Roylance et al. spent considerable time investigating the ballistic performance of textile structures when subjected to transverse impact [104109]. This work was especially focussed on the development of numerical methods that could simulate shock wave propagation and model the interactions due to the influence of 
fibre crossover points. Later work conducted in 1995 [110], presented more advanced numerical models that could be applied to multi-layer fabric panels, and model fabric imperfections such as yarn slippage at fibre crossover points.

Similar work was also investigated by other researchers; in 1995, Parga-Landa and Hernandez-Olivares [111] developed an analytical model for predicting the impact behaviour of soft armour where the ballistic behaviour of the yarn was used to predict the overall impact response of the woven fabric. In the same year, Shim et al. [112] idealised the fabric as a network of viscoelastic fibre elements and a three-element viscoelastic constitutive model was used to represent polymer behaviour thus reflecting intermolecular and intramolecular bond strength as well as the static mechanical properties of the fibres. In 1997, Shockey [113], modelled the individual yarns of the fabric material, and in 1998, Billon [114], studied ballistic impact using a similar approach to Shim et al. [112].

Continuation of this work was presented in 2003, by Gu [115] who developed an analytical model to calculate the decrease of kinetic energy and residual velocity of a projectile when penetrating multi-layered planar plain-woven fabrics. This analytical approach was based on the energy conservation law. In the following year, $\mathrm{Gu}$ and $\mathrm{Xu}$ [116] presented a simplified numerical model in which LS-DYNA was used to simulate the impact interaction between projectile and inclined lamina. The residual velocity of projectile perforating the 3D braided composite was calculated from the sum of kinetic energy loss of the projectile. The simulations utilised the Chang-Chang failure criterion [103].

During the late 1980's and early 90's, Cantwell and Morton performed several studies into the high velocity impact response of CFRP composites. In 1985, they used a gas gun arrangement to impact test CFRP laminates [117], and in 1988, Cantwell [118] investigated the influence of target geometry. In 1989, Cantwell and Morton [119] undertook an assessment of the influence of the projectile mass upon the impact response and subsequent load-bearing capability of a composite structure and found that for a given impact energy, decreasing the impactor mass resulted in greater levels of incurred damage and, therefore, poorer post-impact properties.

Conclusions from this study and from several other papers, which compare low velocity and high velocity impacts [120-122], Cantwell and Morton state that fast-moving projectiles induce a very localised form of target response in which most of the incident energy of the projectile is dissipated immediately adjacent to the point of impact, by essentially shearing the fibres and therefore high velocity impact loading by a small projectile is generally more detrimental to the integrity of a composite structure than low velocity drop-weight impact loading.

In 1989, Hall [123] continued some research work to determine most suitable material for the glass reinforced plastic/foam sandwich composite hull of a Royal Australian Navy's Minehunter ship [30]. The investigation included the underwater shock testing of composite panels and full scale hull sections to understand the failure modes when subjected to blast loading. 
Since this study was intended for a military purpose, Hall, comments that the gathering of similar test data from other research programs was often difficult because test results were usually classified. However, Hall argues that this presented no hindrance to this research work since the diversity of composite structures tested in other programs would be difficult to correlate to the design uses in this study, mainly because the mechanical strength and structural response is influenced by the positioning of strengthening ribs and the types of material used. Therefore, there is a strong requirement for experimental testing for predicting the performance of a new structure.

Several experimental tests were conducted in a freshwater pond (depth $6 \mathrm{~m}$ ) which subjected submerged test panels to an explosive charge with known characteristics at a predetermined distance from the centre of the test piece. The distance was subsequently decreased after each explosion until it was determined that the sample had failed.

Two key considerations for the design of the experiment were (i) simulating the water/air interface of a ship's hull by sealing the test panel into a steel box with an air gap at the rear of the panel, and (ii) ensuring that the positioning of the test panel in the water minimised the occurrence of shock wave reflection from the bottom of the test pond, but also deep enough to minimise any shock wave energy reduction cause by venting or surface cut-off effects.

A full-scale hull test section experiment was also conducted in large flooded quarries (depth $10 \mathrm{~m}$ ), but these tests used weighted explosive charges which detonated at know distances from the hull.

In addition to the usual composite failure modes, e.g. fibre/matrix debonding, sandwich composites have the additional weakness of possible failure within the core material or skin/core interface. For marine applications the structure must also be able to withstand seainduced motion and fatigue as well as the requirement to withstand underwater explosive effects in the case of military ships.

This study was specific to the Royal Australian Navy's requirement to develop a new ship and therefore, once the experimental data had been gathered there was no need to develop numerical methods for predicting the performance of different designs. This is something that would be of great interest to the marine industry since numerical methods would speed up the design process and also allow fewer experimental tests to be conducted which would lead to great cost savings in future design programs.

A way to develop standard numerical methods would be to test composite specimens with a shock tube experimental rig in order to produce uniform shock waves as used by Stoffel et al. [124-128]. Although these papers deal with thin circular metal plates when subjected to shock waves, the experimental shock tube arrangement could be modified to allow the shock wave to travel though water as opposed to air in the low pressure chamber. This 
would afford greater control of the experiment and the uniformity of the shock wave would assist in the verification of numerical simulations.

In 1995, Graham [129] studied composite pressure hulls for deep ocean submersibles and used finite element methods for the analysis of cylindrical components under external pressure to evaluate failure criteria.

Similar numerical work was conducted in 1997 by McCoy and Sun [130] who performed an analysis of the fluid-structure interaction of a $\left[0^{\circ} / 90^{\circ}\right] 600$ graphite-epoxy composite cylinder when subjected to underwater blast loading. The paper discusses some of the advantages of using composite materials in marine and submarine structural applications such as the benefits of light weight composites replacing conventional materials thereby reducing the hull weight to water displacement ratio which is favourable for performance enhancements such as increased payload, range and endurance.

For the numerical investigation, McCoy and Sun, utilised the commercially available ABAQUS finite element software. The initial part of the investigation was to validate the use of the effective modulus theory/global-local method in dynamics applications. This was done by constructing two FE models; one based on the effective properties and the other on the exact local material properties. Each model was for a $\left[0^{\circ} / 90^{\circ}\right]_{100}$ graphite-epoxy composite cylinder with inner radius $5 \mathrm{~m}$ and constructed using 1000 axisymmetrical elements. The applied blast loading was based on an initial ramp loading followed by exponential pressure decay. By comparing the resulting stress distributions from the two simulations is was found that there was an excellent agreement between them. The numerical investigation then proceeded to study a thicker section of graphite-epoxy composite cylinder with inner radius $3 \mathrm{~m}$ and staking sequence of $\left[0^{\circ} / 90^{\circ}\right]_{600}$. Note that only half of the cylinder is modelled due to symmetry.

The analysis was carried out with and without fluid-structure coupling and it was shown that the coupling had a significant effect on the resulting stress distribution. The uncoupled solution gave results throughout the analysis that where significantly higher than the coupled method and this was due to the omitted damping effect of the structure caused by the fluid-structure uncoupling. This paper also gives a very good description of the physical processes that occur (i.e. pressure pulses) when explosions take place underwater.

In 1997, Chen et al. [131] used the Lagrangian smooth particle hydrodynamics (SPH) method to simulate high-velocity impact damage and penetration of graphite/epoxy laminated composite structures when impacted by a steel projectile. For the purposes of this paper the author's intent was to demonstrate that SPH could be a viable tool for predicting the response of fibre-reinforced structures.

The authors state that the SPH method, which was developed in the late 70's, had been applied successfully to astrophysics and shock physics problems and in the early 1990's the software was also used to solve for hyper-velocity impacts. The main advantage for using the SPH method is there is no requirement for an underlying grid and therefore numerical 
problems such as mesh entanglement and distortion can be avoided. SPH also has the ability to simulate failure modes of composite materials such as fibre breakage, matrix cracking and determine ballistic limits and residual projectile velocities.

The paper briefly discusses some of the physics involved with the development of SPH theoretical models and states that little work has been done to account for non-homogeneity and anisotropy of composites.

Chen et al. state that some of the disadvantages associated with previous methods have been the use of Hill's orthotropic plasticity theory to describe the plastic behaviour of composites. This theory is based on two assumptions; (i) hydrostatic stress does not influence plastic deformation, and (ii) plastic dilation is incompressible. It is these assumptions that Chen et al. suggest are not suitable for the analysis of fibre composite materials. Therefore, for the purposes of the paper, Chen et al. proposed a new threedimensional anisotropic elasto-plastic model, an equation of state and a dynamic failure criterion for unidirectional composites.

Due to computing limitations, it was acknowledged by the authors that two simplifications to the numerical model needed to be made. One was to model only one quarter of the plate despite the fact that a quasi-isotropic laminate would exhibit a bending-twisting coupling. The second was to assign only one particle per layer which resulted in a numerical model that was too coarse to obtain a convergent solution. From the conclusions drawn out in this paper it was determined that the SPH method agreed relatively well with experimental observations. The paper also makes recommendations for further work to improve the technique for accurate structural prediction of composites.

In 1998, Chen and Medina [132] investigated the perforation effects of projectile shape on laminated Boron/Aluminium composites. For their study they considered four different types of projectile; one circular, and three rectangular rods. All projectiles had the same cross-sectional area, but the three rectangular rods each had a different height to width ratio. Since it was the perforation effects that were of interest, all impact velocities were conducted above the ballistic limit of the composite.

In 1999, Türkmen and Mecitoglu studied the response of stiffened carbon fibre plates [133] and the dynamic response of fibre glass composite plates [134] when subjected to a blast load. The experimental apparatus used in these investigations consisted of a long circular cylindrical shock tube in which a shock wave was developed by detonating a mixture of liquid propane gas and oxygen. The numerical solutions were performed using ANSYS finite element software for which the authors reported good agreement with experimental values. In the same year, Türkmen [135] compared theoretical solutions to those provided by finite element methods and in 2002, Türkmen [136] also compared theoretical solutions to experimental values and discussed that some discrepancies between analytical, numerical and experimental results could be attributed to the fact that simulations of the blast load assume contact of the entire surface of the test specimen at the same time whereas in a real experimental situation the blast load will reach the centre of the plate first. 
In 2001, Hohler et al. [137] investigated the performance of oblique, ceramic/metal, bilayer composite armours. To represent the impact from a generic medium calibre cannon long rod projectile, the experiments were performed at an approximate half scale, and predominantly at $1450 \mathrm{~m} / \mathrm{s}$. Further tests were also conducted at $2200 \mathrm{~m} / \mathrm{s}$ to study the armour response against possible future ordnance velocity impacts.

In 2002, MacDonald [138] performed an experimental and numerical investigation into high velocity impact of aircraft metal structures. The numerical simulations were conducted in LS-DYNA using a tied-nodes-with-failure modelling approach for penetration which had previously been assessed by Knight et al. [139].

In 2003, Lim et al. [140] used the non-linear, explicit, three-dimensional finite-element code DYNA3D to model the ballistic impact of plain-woven Twaron fabric armour. The authors stated that numerical models proposed by previous researchers have simplified the problem due to computational limitations, despite a more accurate solution that could be presented if individual yarn crossovers were modelled.

Twaron is made from paraphenylene terepthalamide (PPTA) fibres and is similar to Kevlar because of their high-strength fibres, these woven fabrics offer good impact resistance and are suitable for applications such as bullet-proof vests and reinforcing layers on composite structures.

For this study, the projectile was modelled using solid elements, and the target using membrane elements. Since the length and width of the target is much greater than the thickness, a two-dimensional plane stress situation is assumed and therefore the shellmembrane approach to this problem can be justified.

The material model for the target utilised a strain-rate dependent plasticity model (Material Type 19 in DYNA3D), because this could be modified to select parameters such as Young's modulus and failure stress to be a function of strain rate, and therefore this strainrate-sensitive failure criterion could provide a representation of the viscoelastic effects of the composite fabric. The numerical analysis also took advantage of the fact that the thickness of the test specimen was much less than the height and width and therefore a twodimensional plane stress condition was assumed.

The numerical solutions for ballistic limit, residual velocity, energy absorption and transverse deflection profiles were compare to experimentally determined values and it was found that as the impact velocity became greater than $400 \mathrm{~m} / \mathrm{s}$, the impact and residual velocities were close in value. The explanation for this was that at high impact velocities the strain rates were very high and the material's ability to resist penetration (failure stress) would be at a maximum and therefore the energy absorbed would be relatively small.

The authors acknowledge that there are several limitations to the numerical model such as the omission of frictional effects between the yarn crossover points and unravelling yarns. 
Also due to simplifications, the need to refine the way dynamic properties are determined from strain rates requires refinements for greater accuracy.

Within the last few decades, several authors have worked on the development of continuum damage mechanics (CDM) material laws for integration into composite failure FE codes [141-143]. In the early 2000's, Johnson et al. started to develop a CDM approach based on the methods developed by Ladevèze and Le Dantec [141] and Allix and Ladevèze [142]. Early work conducted in 2001 focused on material modelling and numerical simulations of fabric reinforced composites in the low velocity impact regime [144, 145]. Later work addressed the high velocity impact of composite shell structures such as a typical wing leading edge when subjected to simulated soft body impact such as a bird strike [146], and in 2006, Johnson and Holzapfel [147] conducted a numerical validation of high velocity impact of shell structures by implementing a CDM code which modelled delamination by allowing damage and fracture to be introduced when a delamination failure criterion was reached.

\section{HYPER VELOCITY IMPACT}

In 1991, Schonberg and Walker [148] experimentally investigated several different composite materials for their ability to prevent the perforation of the spacecraft pressure walls in multi-wall systems subjected to hypervelocity projectile impact. This was in response to a previous work in which Schonberg [149] had studied single-wall systems and found that there was no significant advantage in using composites over aluminium. The present study concluded that for multi-wall systems there was an advantage, which was mainly due to the composite material being able to absorb and channel the energy of the impacting primary debris clouds along material layers that are not available in metallic materials. This experimental investigation was conducted on an instrumented two-stage light-gas gun capable of launching $2.5-12.7 \mathrm{~mm}$ projectiles at velocities of $2-8 \mathrm{~km} / \mathrm{s}$. In 2000, Schonberg [150] reported that composites are most effective when used as the middle wall of a triple-wall system.

In 1995, Silvestrov et al. [151] presented the results on the damage of three different types of fibre reinforced epoxy laminated composite when under the impact of steel and glass projectiles at velocities in the region of $8-11 \mathrm{~km} / \mathrm{s}$. Work completed in the years that followed focused more on hypervelocity impact of ceramic/aluminium composites in order to develop materials that offered greater penetration resistance against meteoroid and debris impacts for applications such as space vehicles [152, 153].

In 1999 and 2001, Lamontagne et al. [154, 155] published their work on the normal and oblique hypervelocity impacts of carbon fibre/PolyEtherEtherKetone (PEEK) composites. The main purpose of their studies was to add oblique impact data for PEEK composites to the University of Toronto Institute for Aerospace Studies (UTIAS) database. The impact tests were conducted on a light gas gun in the UK and a two-stage light gas gun in the US. 
The effects that projectile density, impact angle and energy had on the resultant composite damaged was studied.

For the initial tests, the composite specimens were clamped to an aluminium holding plate which contained a circular cut-out. It is interesting to note that in later experiments the holding plate was modified to a rectangular cut-out, since it was found that the circular cutout had provided too much support and resulted in a reduction of realistic impact delamination propagation.

Further areas of research are stated in the paper, and the authors expressed their intention to develop a hyper-velocity impact damage model for PEEK composites. No numerical analysis was performed for these tests.

During this time, Tennyson and Lamontagne [156] published a separate paper which was based on the work discussed above in $[154,155]$, but focused more closely on the damaging effects of ejecta plumes after hypervelocity impacts. The ejecta originate from two sources; the first is from the disintegrated material of the test specimen and the second is from the projectile.

A key feature of the studies was how for oblique impacts, a small turning angle, $\varepsilon$, was observed when comparing the estimated centre of mass of the ejecta damage zone to the initial projectile velocity vector. The paper suggests that the turning angle is independent of ply thickness, but due to the limited amount of data this would need further verification. The importance of investigating the damage caused by ejecta plumes needs to be understood, especially with regard to the positioning of components behind possible impact surfaces. No predictive models were proposed in this paper.

In 2003, Lee [157] used the SPH method (which Lee and Yoo [158] had previously verified) to numerically investigate hypervelocity $60^{\circ}$ oblique impact of thick alumina/aluminium composite targets and then compare the results to published experimental data.

There has been great interest in ceramic/metal composite armour combinations because the metal back plate delays tensile failure in the ceramic which leads to increased projectile erosion and enhances the ballistic performance. The metal backing plate also has the additional benefit of absorbing kinetic energy from ceramic fragments.

This study looks at composite targets which are relatively thick, with depths 40 times the diameter of the projectile. The author noted that as a result, the damage mechanisms of projectile erosion, crack propagation, and backing plate failure may not be observed as for thin targets which are approximately twice the diameter of the projectile.

Unfortunately, the published experimental test data that Lee chose to compare the numerical solutions to was not entirely suitable since the test data was for thin test specimens and therefore comparison was difficult. 
Overall, Lee concluded that for high velocity impacts of thick targets, the metal backing plate had reduced influence on the impact performance of the ceramic.

\section{CONCLUSIONS}

The impact study of composites is important because many automotive and aerospace applications are utilising full-composite structures as a viable alternative to the more conventional metal constructions. Despite composites having many advantages over metal, i.e. high strength to weight ratio, there is still the problem of detecting impact damage. Metals will display some form of visible surface damage when subjected to impact, however composite impact damage is usually hidden inside the material, particularly for low velocity impact. These undetected material failures can greatly reduce the strength of the composite and can occur easily during production and maintenance operations.

Although some authors have conducted their work in accordance with some form of testing standard (British Standards, CRAG, Airbus and Boeing) there continues to be a lack of a universally accepted method for testing composites and this suggests composite impact characterisation presents greater challenges than the testing of metals. Perhaps in time as experience with composites increases, standard methods will be developed. From previous experiments researchers have demonstrated the use of different experimental apparatus and specimen geometries when assessing similar impact properties. Perhaps it is the adaptability of composite material construction and applications that present too many variables to be able to standardise testing procedures, therefore each new development in materials and applications will merit its own 'tailor' suited investigation.

This review also demonstrates that the vast majority of previous research work for composite impact damage has been performed for low velocity regimes; this is probably due to the constraints of technique and costs of high velocity investigations.

Much research has been done for normal impact with limited data presented for oblique impacts despite this being the most common type encountered. This suggests that previous work has considered a 'worse case scenario' and therefore, normal impact investigation was the most appropriate choice as this would cause the most damage and from a structural design point this would be the most interesting. The oblique impact data would be of interest for composite components which are already in use and have been subjected to some damage because in this case, the engineer would want to know if the damage caused would degrade the performance of the composite to an unacceptable level at which point the component could be replaced or repaired.

It appears there is also a need for more low velocity impact testing to be completed that more accurately simulates the in-service conditions composite materials will be subjected to, especially with the theoretical and experimental understanding of how pre-stress affects composite structures. 
A great deal of the research reviewed has been conducted on flat plate specimens. It can be argued that for most composite applications, especially in the aerospace and marine industry, composites will be utilised on curved structures such as laminated aircraft wings, horizontal / vertical stabiliser skins, and ship hulls, and therefore more work could be performed in this area.

Some research has investigated underwater blast loading of composites, but this work has predominantly being experimental and therefore there is still a vast subject area to be explored, especially due to the relatively recent developments in F.E. analysis software which has permitted the solution of fluid-structure interaction problems.

\section{REFERENCES}

1. Hazell EA. Measurement of the effects of strain rate on mechanical properties of composites part 1 - Instrumented Hounsfield tensometers. Composites 1970;1(6):362-365. 2. Hazell EA. Measurement of the effects of strain rate on mechanical properties of composites: part 2. instrumented avery izod pendulum impact machine. Composites 1971;2(2):110-113.

3. Hancox NL. Izod impact testing of carbon-fibre-reinforced plastics. Composites 1971;2(1):41-45.

4. Wells H, Hancox NL. Stiffening and strengthening GRP beams with CFRP. Composites 1971;2(3):147-151.

5. Hancox NL, Wells H. Izod impact properties of carbon-fibre/glass-fibre sandwich structures. Composites 1973;4(1):26-30.

6. Harris B, Bunsell AR. Impact properties of glass fibre/carbon fibre hybrid composites. Composites 1975;6(5):197-201.

7. Bunsell AR, Harris B. Hybrid carbon and glass fibre composites. Composites 1974;5(4):157-164.

8. Perry JL, Adams DF. Charpy impact experiments on graphite/epoxy hybrid composites. Composites 1975;6(4):166-172.

9. Rogers KF, Sidey GR, Kingston-Lee DM. Ballistic impact resistance of carbon-fibre laminates. Composites 1971;2(4):237-241.

10. Wrzesien A. Improving the impact resistance of glass-fibre composites. Composites 1972;3(4):172-174.

11. Thomas WF. Factors affecting the impact strength of glass-fibre-reinforced polyester composites. Composites 1973;4(3):105-110.

12. Ross CA, Sierakowski RL. Studies on the impact resistance of composite plates. Composites 1973;4(4):157-161.

13. Bader MG, Ellis RM. The effect of notches and specimen geometry on the pendulum impact strength of uniaxial CFRP. Composites 1974;5(6):253-258.

14. McQuillen EJ, Gause LW, Llorens RE. Low velocity transverse normal impact of graphite epoxy composite laminates. J Compos Mater 1976;10:79-91. 
15. Cantwell WJ, Curtis PT, Morton J. Impact and subsequent fatigue damage growth in carbon fibre laminates. Int J Fatigue 1984;6(2):113-118.

16. Cantwell W, Curtis P, Morton J. Post-impact fatigue performance of carbon fibre laminates with non-woven and mixed-woven layers. Composites 1983;14(3):301-305.

17. Cantwell WJ, Curtis PT, Morton J. An assessment of the impact performance of CFRP reinforced with high-strain carbon fibres. Compos Sci Technol 1986;25(2):133-148.

18. Cantwell WJ, Morton J. Geometrical effects in the low velocity impact response of CFRP. Compos Struct 1989;12(1):39-59.

19. Cantwell WJ, Morton J. An assessment of the residual strength of an impact-damaged carbon fibre reinforced epoxy. Compos Struct 1990;14(4):303-317.

20. Curtis PT. An investigation of the mechanical properties of improved carbon fibre composite materials. J Compos Mater 1987;21:1118-1144.

21. Morton J, Godwin EW. Impact response of tough carbon fibre composites. Compos Struct 1989;13(1):1-19.

22. Caprino G, Crivelli Visconti I, Di Ilio A. Elastic behaviour of composite structures under low velocity impact. Composites 1984;15(3):231-234.

23. Caprino G, Crivelli Visconti I, Di Ilio A. Composite materials response under lowvelocity impact. Compos Struct 1984;2(3):261-271.

24. Kumar P, Narayanan MD. Energy dissipation of projectile impacted panels of glass fabric reinforced composite. Compos Struct 1990;15(1):75-90.

25. Kumar P, Rai B. Impact damage on single interface GFRP laminates - An experimental study. Compos Struct 1991;18(1):1-10.

26. Kumar P, Rai B. Delaminations of barely visible impact damage in CFRP laminates. Compos Struct 1993;23(4):313-318.

27. Found MS, Howard IC. Single and multiple impact behaviour of a CFRP laminate. Compos Struct 1995;32(1-4):159-163.

28. Found MS, Howard IC, Paran AP. Size effects in thin CFRP panels subjected to impact. Compos Struct 1997;38(1-4):599-607.

29. Found MS, Howard IC, Paran AP. Interpretation of signals from dropweight impact tests. Compos Struct 1998;42(4):353-363.

30. Hall DJ, Robson BL. A review of the design and materials evaluation programme for the GRP/foam sandwich composite hull of the RAN minehunter. Composites 1984;15(4):266-276.

31. Kim C-G, Jun E-J. Impact resistance of composite laminated sandwich plates. J Compos Mater 1992;26(15):2247-2261.

32. Nemes JA, Simmonds KE. Low-velocity impact response of foam-core sandwich composites. J Compos Mater 1992;26(4):500-519.

33. Lee LJ, Huang KY, Fann YJ. Dynamic responses of composite sandwich plate impacted by a rigid ball. J Compos Mater 1993;27(13):1238-1256.

34. Caprino G, Teti R. Impact and post-impact behavior of foam core sandwich structures. Compos Struct 1994;29(1):47-55.

35. Mines RAW, Worrall CM, Gibson AG. The static and impact behaviour of polymer composite sandwich beams. Composites 1994;25(2):95-110.

36. Mines RAW, Jones N. Approximate elastic-plastic analysis of the static and impact behaviour of polymer composite sandwich beams. Composites 1995;26(12):803-814. 
37. Wu CL, Sun CT. Low velocity impact damage in composite sandwich beams. Compos Struct 1996;34(1):21-27.

38. Herup EJ, Palazotto AN. Low-velocity impact damage initiation in graphite/epoxy/Nomex honeycomb-sandwich plates. Compos Sci Technol 1998;57(12):1581-1598.

39. Mines RAW, Worrall CM, Gibson AG. Low velocity perforation behaviour of polymer composite sandwich panels. Int J Impact Eng 1998;21(10):855-879.

40. Roach AM, Evans KE, Jones N. The penetration energy of sandwich panel elements under static and dynamic loading. Part I. Compos Struct 1998;42(2):119-134.

41. Roach AM, Jones N, Evans KE. The penetration energy of sandwich panel elements under static and dynamic loading. Part II. Compos Struct 1998;42(2):135-152.

42. Anderson T, Madenci E. Experimental investigation of low-velocity impact characteristics of sandwich composites. Compos Struct 2000;50(3):239-247.

43. Palazotto AN, Herup EJ, Gummadi LNB. Finite element analysis of low-velocity impact on composite sandwich plates. Compos Struct 2000;49(2):209-227.

44. Hoo Fatt MS, Park KS. Dynamic models for low-velocity impact damage of composite sandwich panels - Part A: Deformation. Compos Struct 2001;52(3-4):335-351.

45. Hoo Fatt MS, Park KS. Dynamic models for low-velocity impact damage of composite sandwich panels - Part B: Damage initiation. Compos Struct 2001;52(3-4):353-364.

46. Found MS, Howard IC, Paran AP. Impact behaviour of stiffened CFRP sections. Compos Struct 1997;39(3-4):229-235.

47. Found MS, Howard IC, Paran AP. Impact perforation of thin stiffened CFRP panels. Compos Struct 2000;48(1-3):95-98.

48. Found MS, Howard IC, Paran AP. Modelling the impact behaviour of thin CFRP panels. Key Eng Mat 2002;221-222:187-196.

49. Pavier MJ, Clarke MP. Experimental techniques for the investigation of the effects of impact damage on carbon-fibre composites. Compos Sci Technol 1995;55(2):157-169. 50. Ganapathy S, Tripathy B, Rao KP. Damage and its growth in laminated composite circular/rectangular plates undergoing large deformations. Compos Struct 1995;32(14):367-373.

51. Venkatesh A, Rao KP. A doubly curved quadrilateral finite element for the analysis of laminated anisotropic thin shells of revolution. Comput Struct 1980;12(6):825-832. 52. Tsai SW, Wu EM. A general theory of strength for anisotropic materials. J Compos Mater 1971;5:58-80.

53. Ganapathy S, Rao KP. Interlaminar stresses in laminated composite plates, cylindrical/spherical shell panels damaged by low-velocity impact. Compos Struct 1997;38(1-4):157-168.

54. Ganapathy S, Rao KP. Failure analysis of laminated composite cylindrical/spherical shell panels subjected to low-velocity impact. Comput Struct 1998;68(6):627-641.

55. Madjidi S, Arnold WS, Marshall IH. Damage tolerance of CSM laminates subject to low velocity oblique impacts. Compos Struct 1996;34(1):101-116.

56. Kim SJ, Goo NS. Dynamic contact responses of laminated composite plates according to the impactor's shapes. Computers \& Structures 1997;65(1):83-90.

57. Kim SJ, Goo NS, Kim TW. The effect of curvature on the dynamic response and impact-induced damage in composite laminates. Compos Sci Technol 1997;57(7):763-773. 
58. Kistler LS, Waas AM. Impact response of cylindrically curved laminates including a large deformation scaling study. Int J Impact Eng 1998;21(1-2):61-75.

59. Kistler LS, Waas AM. Experiment and analysis on the response of curved laminated composite panels subjected to low velocity impact. Int J Impact Eng 1998;21(9):711-736. 60. Kistler LS, Waas AM. On the response of curved laminated panels subjected to transverse impact loads. Int J Solids Struct 1999;36(9):1311-1327.

61. Sun CT, Chattopadhyay S. Dynamic response of anisotropic laminated plates under initial stress to impact of a mass. J Appl Mech 1975;6:693-698.

62. Matsuhashi H, Graves MJ, Dugundji J, Lagace PA. Effect of membrane stiffening in transient impact analysis of composite laminated plates. Proc. 34

AIAA/ASME/ASCE/AHS/ASC SDM, AIAA, 1993, p. 2668-2678.

63. Lagace PA, Wolf E. Impact damage resistance of several laminated material systems. AIAA J 1995;33(6):1109-1113.

64. Ambur DR, Starnes JH, Pradsad CB. Influence of transverse shear and large-

deformation effects on the low-speed impact response of laminated composite plates.

NASA TM 107753, 1993.

65. Prasad CB, Ambur DR, Starnes JH. Response of laminated composite plates to lowspeed impact by different impactors. AIAA J 1994;32(6):1270-1277.

66. Collombet F, Lalbin X, Bonini J, Lataillade JL. Contact impact techniques for the study of impacted laminated structures. Math Comput Model 1998;28(4-8):171-184.

67. Collombet F, Lalbin X, Bonini J, Martin V, Lataillade JL. Damage criteria for the study of impacted composite laminates. Compos Sci Technol 1998;58(5):679-686.

68. Collombet F, Lalbin X, Lataillade JL. Impact behavior of laminated composites:

Physical basis for finite element analysis. Compos Sci Technol 1998;58(3-4):463-478.

69. Leylek Z, Scott ML, Georgiadis S, Thomson RS. Computer modelling of impact on curved fibre composite panels. Compos Struct 1999;47(1-4):789-796.

70. Schoeppner GA, Abrate S. Delamination threshold loads for low velocity impact on composite laminates. Compos Part A-Appl S 2000;31(9):903-915.

71. Hou JP, Petrinic N, Ruiz C, Hallett SR. Prediction of impact damage in composite plates. Compos Sci Technol 2000;60(2):273-281.

72. Airbus Industrie. Fibre reinforced plastics-determination of compression strength after impact. Airbus Industrie Test Method 1.0010, 1993, Issue 1, February.

73. Boeing. Advanced composite tests. Boeing Specification Support Standard, BSS7260, Rev C, 1998.

74. Hou JP, Petrinic N, Ruiz C. A delamination criterion for laminated composites under low-velocity impact. Compos Sci Technol 2001;61(14):2069-2074.

75. Abrate S. Modeling of impacts on composite structures. Compos Struct 2001;51(2):129-138.

76. Mili F, Necib B. Impact behavior of cross-ply laminated composite plates under low velocities. Compos Struct 2001;51(3):237-244.

77. Azouaoui K, Rechak S, Azari Z, Benmedakhene S, Laksimi A, Pluvinage G. Modelling of damage and failure of glass/epoxy composite plates subject to impact fatigue. Int $\mathbf{J}$ Fatigue 2001;23(10):877-885.

78. Jones R, Williams JF, Tay TE. Is fatigue testing of impact damaged laminates necessary? Compos Struct 1987;8(1):1-12. 
79. Wyrick DA, Adams DF. Damage sustained by a carbon/epoxy composite material subjected to repeated impact. Composites 1988;19(1):19-27.

80. Wyrick DA, Adams DF. Residual strength of a carbon/epoxy composite material subjected to repeated impact. J Compos Mater 1988;22:749-765.

81. Clark G. Modelling of impact damage in composite laminates. Composites 1989;20(3):209-214.

82. Jang BP, Kowbel W, Jang BZ. Impact behavior and impact-fatigue testing of polymer composites. Compos Sci Technol 1992;44(2):107-118.

83. Lee BL, Liu DS. Cumulative damage of fibre-reinforced elastomer composites under fatigue loading. J Compos Mater 1994;28(13):1261-1286.

84. Mahinfalah M, Skordahl RA. The effects of hail damage on the fatigue strength of a graphite/epoxy composite laminate. Compos Struct 1998;42(2):101-106.

85. Tai NH, Yip MC, Lin JL. Effects of low-energy impact on the fatigue behavior of carbon/epoxy composites. Compos Sci Technol 1998;58(1):1-8.

86. Tai NH, Ma CCM, Lin JM, Wu GY. Effects of thickness on the fatigue-behavior of quasi-isotropic carbon/epoxy composites before and after low energy impacts. Compos Sci Technol 1999;59(11):1753-1762.

87. Caprino G, Lopresto V, Scarponi C, Briotti G. Influence of material thickness on the response of carbon-fabric/epoxy panels to low velocity impact. Compos Sci Technol 1999;59(15):2279-2286.

88. Caprino G, Lopresto V. The significance of indentation in the inspection of carbon fibre-reinforced plastic panels damaged by low-velocity impact. Compos Sci Technol 2000;60(7):1003-1012.

89. Caprino G, Lopresto V. On the penetration energy for fibre-reinforced plastics under low-velocity impact conditions. Compos Sci Technol 2001;61(1):65-73.

90. Caprino G, Langella A, Lopresto V. Elastic behaviour of circular composite plates transversely loaded at the centre. Compos Part A-Appl S 2002;33(9):1191-1197.

91. Caprino G, Langella A, Lopresto V. Indentation and penetration of carbon fibre reinforced plastic laminates. Compos Part B-Eng 2003;34(4):319-325.

92. Krishnamurthy KS, Mahajan P, Mittal RK. Impact response and damage in laminated composite cylindrical shells. Compos Struct 2003;59(1):15-36.

93. Krishnamurthy KS, Mahajan P, Mittal RK. A parametric study of the impact response and damage of laminated cylindrical composite shells. Compos Sci Technol

2001;61(12):1655-1669.

94. Choi HY, Downs RJ, Chang F-K. A new approach toward understanding damage mechanisms of laminated composites due to low-velocity impact: Part I - experiments. J Compos Mater 1991;25(8):992-1011.

95. Choi HY, Wu H-YT, Chang F-K. A new approach toward understanding damage mechanisms of laminated composites due to low-velocity impact: Part II - analysis. J Compos Mater 1991;25(8):1012-1038.

96. Choi HY, Chang F-K. A model for predicting damage in graphite/epoxy laminated composites resulting from low-velocity point impact. J Compos Mater 1992;26(14):21342169. 
97. Whittingham B, Marshall IH, Mitrevski T, Jones R. The response of composite structures with pre-stress subject to low velocity impact damage. Compos Struct 2004;66(1-4):685-698.

98. Mitrevski T, Marshall IH, Thomson R, Jones R, Whittingham B. The effect of impactor shape on the impact response of composite laminates. Compos Struct 2005;67(2):139-148. 99. Zhang Y, Zhu P, Lai X. Finite element analysis of low-velocity impact damage in composite laminated plates. Mater Design 2006;27(6):513-519.

100. Her S-C, Liang Y-C. The finite element analysis of composite laminates and shell structures subjected to low velocity impact. Compos Struct 2004;66(1-4):277-285.

101. Zhao GP, Cho CD. Damage initiation and propagation in composite shells subjected to impact. Compos Struct 2007;78(1):91-100

102. Hosseinzadeh R, Shokrieh MM, Lessard L. Damage behavior of fiber reinforced composite plates subjected to drop weight impacts. Compos Sci Technol 2006;66(1):61-68. 103. Chang F-K, Chang K-Y. A progressive damage model for laminated composites containing stress concentrations. J Compos Mater 1987;21:834-855.

104. Roylance D, Wilde AF, Tocci GC. Ballistic impact of textile structures. Text Res J 1973;43:34-41.

105. Roylance D. Wave propagation in a viscoelastic fiber subjected to transverse impact. J Appl Mech 1973;40(E):143-148.

106. Roylance D. Ballistics of transversely impacted fibers. Text Res J 1977;47:679-684. 107. Roylance D, Wang S-S. Penetration mechanics of textile structures: Influence of nonlinear viscoelastic relaxation. Polym Eng Sci 1978;18:1068-1072.

108. Roylance D. Stress wave propagation in fibres: Effect of crossovers. Fibre Sci Technol 1980;13(5):385-395.

109. Roylance D, Wang S-S. Influence of fibre properties on ballistic penetration of textile panels. Fibre Sci Technol 1981;14(3):183-190.

110. Roylance D, Chammas P, Ting J, Chi H, Scott B. Numerical modeling of fabric impact: Proceedings of the national meeting of the American Society of Mechanical Engineers (ASME), San Francisco, October 1995.

111. Parga-Landa B, Hernandez-Olivares F. An analytical model to predict impact behaviour of soft armours. Int J Impact Eng 1995;16(3):455-466.

112. Shim VPW, Tan VBC, Tay TE. Modelling deformation and damage characteristics of woven fabric under small projectile impact. Int J Impact Eng 1995;16(4):585-605. 113. Shockey DA, Giovanola JH, Simons JW, Erlich DC, Kolpp RW, Skaggs SR. Advanced armour technology: Application potential for engine fragment barrier for commercial aircraft. US Department of Transport, Federal Aviation Administration 1997;DOT/FAA/AR97-53

114. Billon H. A model for ballistic impact on soft armour. DSTO Aeronautical \& Maritime Research Laboratory 1998;DSTO-TR-0730

115. Gu B. Analytical modeling for the ballistic perforation of planar plain-woven fabric target by projectile. Compos Part B-Eng 2003;34(4):361-371.

116. Gu B, Xu J. Finite element calculation of 4-step 3-dimensional braided composite under ballistic perforation. Compos Part B-Eng 2004;35(4):291-297.

117. Cantwell WJ, Morton J. Detection of impact damage in CFRP laminates. Compos Struct 1985;3(3-4):241-257. 
118. Cantwell WJ. The influence of target geometry on the high velocity impact response of CFRP. Compos Struct 1988;10(3):247-265.

119. Cantwell WJ, Morton J. The influence of varying projectile mass on the impact response of CFRP. Compos Struct 1989;13(2):101-114.

120. Cantwell WJ, Morton J. Comparison of the low and high velocity impact response of CFRP. Composites 1989;20(6):545-551.

121. Cantwell WJ, Morton J. Impact perforation of carbon fibre reinforced plastic. Compos Sci Technol 1990;38(2):119-141.

122. Cantwell WJ, Morton J. The impact resistance of composite materials - a review. Composites 1991;22(5):347-362.

123. Hall DJ. Examination of the effects of underwater blasts on sandwich composite structures. Compos Struct 1989;11(2):101-120.

124. Stoffel M, Schmidt R, Weichert D. Shock wave-loaded plates. Int J Solids Struct 2001;38(42-43):7659-7680.

125. Stoffel M. Evolution of plastic zones in dynamically loaded plates using different elastic-viscoplastic laws. Int J Solids Struct 2004;41(24-25):6813-6830.

126. Stoffel M. An experimental method to validate viscoplastic constitutive equations in the dynamic response of plates. Mech Mater 2005;37(12):1210-1222.

127. Stoffel M. Shape forming of shock wave loaded viscoplastic plates. Mech Res Commun 2006;33(1):35-41.

128. Stoffel M. An experimental method for measuring the buckling shapes of thin-walled structures. Thin Wall Struct 2006;44(1):69-73.

129. Graham D. Composite pressure hulls for deep ocean submersibles. Compos Struct 1995;32(1-4):331-343.

130. McCoy RW, Sun CT. Fluid-structure interaction analysis of a thick-section composite cylinder subjected to underwater blast loading. Compos Struct 1997;37(1):45-55.

131. Chen JK, Allahdadi FA, Carney TC. High-velocity impact of graphite/epoxy composite laminates. Compos Sci Technol 1997;57(9-10):1369-1379.

132. Chen JK, Medina DF. The effects of projectile shape on laminated composite perforation. Compos Sci Technol 1998;58(10):1629-1639.

133. Türkmen HS, Mecitoglu Z. Dynamic response of a stiffened laminated composite plate subjected to blast load. J Sound Vib 1999;221(3):371-389.

134. Türkmen HS, Mecitoglu Z. Nonlinear structural response of laminated composite plates subjected to blast loading. AIAA J 1999;37(12):1639-1647.

135. Türkmen HS. Structural response of cylindrically curved laminated composite shells subjected to blast loading. ARI - An Int J Physical Eng Sci 1999;51(3):175-180.

136. Türkmen HS. Structural response of laminated composite shells subjected to blast loading: Comparison of experimental and theoretical methods. J Sound Vib 2002;249(4):663-678.

137. Hohler V, Weber K, Tham R, James B, Barker A, Pickup I. Comparative analysis of oblique impact on ceramic composite systems. Int J Impact Eng 2001;26(1-10):333-344. 138. MacDonald BJ. A computational and experimental analysis of high energy impact to sheet metal aircraft structures. J Mater Process Tech 2002;124(1-2):92-98. 
139. Knight NFJ, Jaunky N, Lawson RE, Ambur DR. Penetration simulation for uncontained engine debris impact on fuselage-like panels using LS-DYNA. Finite Elem Anal Des 2000;36(2):99-133.

140. Lim CT, Shim VPW, Ng YH. Finite-element modeling of the ballistic impact of fabric armor. Int J Impact Eng 2003;28(1):13-31.

141. Ladevèze P, LeDantec E. Damage modelling of the elementary ply for laminated composites. Compos Sci Technol 1992;43(3):257-267.

142. Allix O, Ladevèze P. Interlaminar interface modelling for the prediction of delamination. Compos Struct 1992;22(4):235-242.

143. Iannucci L, Dechaene R, Willows M, Degrieck J. A failure model for the analysis of thin woven glass composite structures under impact loadings. Comput Struct 2001;79(8):785-799.

144. Johnson AF. Modelling fabric reinforced composites under impact loads. Compos Part A-Appl S 2001;32(9):1197-1206.

145. Johnson AF, Pickett AK, Rozycki P. Computational methods for predicting impact damage in composite structures. Compos Sci Technol 2001;61(15):2183-2192.

146. Johnson AF, Holzapfel M. Modelling soft body impact on composite structures. Compos Struct 2003;61(1-2):103-113.

147. Johnson AF, Holzapfel M. Influence of delamination on impact damage in composite structures. Compos Sci Technol 2006;66(6):807-815.

148. Schonberg WP, Walker EJ. Use of composite materials in multi-wall structures to prevent perforation by hypervelocity particle impact. Compos Struct 1991;19(1):15-40. 149. Schonberg WP. Hypervelocity impact response of spaced composite material structures. Int J Impact Eng 1990;10(1-4):509-523.

150. Schonberg WP. Protecting spacecraft against orbital debris impact damage using composite materials. Compos Part A-Appl S 2000;31(8):869-878.

151. Silvestrov VV, Plastinin AV, Gorshkov NN. Hypervelocity impact on laminate composite panels. Int J Impact Eng 1995;17(4-6):751-762.

152. Silvestrov VV, Plastinin AV, Pai VV, Yakovlev IV. Hypervelocity impact on isotropic composites with metal or ceramic inclusions. Int J Impact Eng 1997;20(6-10):733-742.

153. Silvestrov VV, Plastinin AV, Pai VV, Yakovlev IV. An investigation of ceramic/aluminium composites as shields for hypervelocity impacts. Int J Impact Eng 1999;23(1, Part 2):859-867.

154. Lamontagne CG, Manuelpillai GN, Taylor EA, Tennyson RC. Normal and oblique hypervelocity impacts on carbon fibre/peek composites. Int J Impact Eng 1999;23(1, Part 2):519-532.

155. Lamontagne CG, Manuelpillai GN, Kerr JH, Taylor EA, Tennyson RC, Burchell MJ. Projectile density, impact angle and energy effects on hypervelocity impact damage to carbon fibre/peek composites. Int J Impact Eng 2001;26(1-10):381-398.

156. Tennyson RC, Lamontagne C. Hypervelocity impact damage to composites. Compos Part A-Appl S 2000;31(8):785-794.

157. Lee M. Hypervelocity impact into oblique ceramic/metal composite systems. Int J Impact Eng 2003;29(1-10):417-424.

158. Lee M, Yoo YH. Analysis of ceramic/metal armour systems. Int J Impact Eng 2001;25(9):819-829. 